\title{
Analisis kritis konstruktif praxis teologi publik Gereja Masehi Injili Halmahera di era otonomi daerah
}

\author{
Julianus Mojau \\ Fakultas Teologi, Universitas Halmahera, Tobelo, Maluku Utara \\ jmojau@gmail.com
}

https://orcid.org/0000

0002-5866-9140

Keywords:

GMIH synod;

Halmahera; praxis;

public theology;

public sphere;

regional autonomy;

otonomi daerah;

ruang publik;

sinode GMIH;

teologi publik

\section{Article History}

Submitted: August 28, 2021

Revised: September 18, 2021

Accepted: Sept. 24, 2021

DOI: https://doi.org/ 10.30995/kur.v7i2.364

Copyright: (O2021, Authors.



Scan this QR,

Read Online

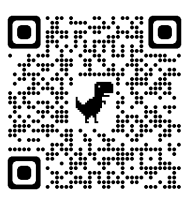

Abstract: This paper highlights the praxis of public theology that resulted from the decisions of the Synod of the Evangelical Christian Church in Halmahera (GMIH Synod) in the context of the era of regional autonomy during the 20022017 ministry period. By using qualitative research methods through library research, this analysis examines theological discourse and living chruch praxis as stated in the decisions of the GMIH Synod. Starting from the analysis of the social function of the Church emphasized by Ricardo F. Nanuru and the praxis of interreligious advocate public theology by Felix Wilfred, this study found that: (a) GMIH ecclesiastical documents have seeded the praxis of interreligious public theology in the form of a series of pastoral recommendations and information on the Church's social services; (b this interreligious public theology advocacy practice needs to have an adequate theological basis and a measurable translation into the practice of living in the GMIH church. This theologically measured programmatic integration helps GMIH demonstrate its ecclesiastical identity as a social-humanist-ecological body of Christ that has an impact on Halmahera's public sphere in the era of regional autonomy which is being overshadowed by the neo-liberal economy and the extractive and exploitive mining economy.

Abstrak: Tulisan ini menyoroti praxis teologi publik hasil keputusan-keputusan persidangan Sinode Gereja Masehi Injili di Halmahera (Sinode GMIH) dalam konteks otonomi daerah selama periode pelayanan 2002-2017. Dengan menggunakan metode penelitian kualitatif melalui jenis penelitian kepustakaan, analisis ini mengkaji wacana teologis dan praxis hidup seperti tertuang dalam keputusan-keputusan Sidang Sinode GMIH. Bertolak dari analisis fungsi sosial Gereja yang ditekankan oleh Ricardo F. Nanuru dan praxis teologi publik advokatif intereligius Felix Wilfred kajian ini menghasilkan: (a) dokumen-dokumen gerejawi GMIH telah membenihkan praxis teologi publik intereligius dalam bentuk serangkaian anjuran pastoral dan informasi pelayanan sosial Gereja; (b) praxis advokasi teologi publik interreligious ini perlu mendapat pendasaran teologis yang memadai dan penerjemahannya yang terukur dalam praktik hidup menggereja GMIH. Pengintegrasian programatis terukur secara teologis ini membantu GMIH meragakan identitas eklesialnya sebagai tubuh sosial-humanis-ekologis Kristus yang berdampak dalam ruang publik Halmahera di era otonomi daerah yang sedang dibayang-bayangi oleh ekonomi neo-liberal dan ekonomi pertambangan ekstraktif dan eksploitatif. 


\section{Pendahuluan}

James Haire mencatat bahwa sejak periode Zending di pulau Halmahera dan pulau-pulau sekitarnya (1866-1949), ruang publik Halmahera selalu dibaca dalam perspektif teologis. la berkata bahwa inisiatif Hendrik van Dijken dan teman-temannya mendirikan sekolah rakyat dan membuka kebun Jemaat di wilayah Galela adalah bentuk pergumulan rangkap teologis Zending untuk mengelola ruang pulau Halmahera dan pulau-pulau sekitarnya pada zamannya. ${ }^{1}$ Liliane Mojau mencatat bahwa karya-karya sosial Zending yang meliputi bidang pertanian dan perkebunan, bidang pendidikan dan kesehatan masih terus berlangsung hingga tahun 1990-an setelah pembentukan Sinode Gereja Masehi Injili di Halmahera (Sinode GMIH) pada 6 Juni 1949. ${ }^{2}$

Memasuki akhir tahun 1990-an (1999) ruang publik Halmahera mengalami perubahan sosial siginifikan seiring dengan pembentukan Provinsi Maluku Utara melalui Undang-Undang Nomor 46 Tahun 1999 (UU Nomor 46 Tahun 1999) dan pembentukan Kabupten/Kota melalui Undang-Undang Nomor 1 Tahun 2003 (UU Nomor 1 Tahun 2003). Ada lima tantangan perubahan signifikan mengiringi pembentukan Provinsi Maluku Utara dan pembentukan kabupaten/ kota dalam Provinsi Maluku Utara tersebut. Pertama, sejumlah kecamatan di pulau Halmahera dan pulau-pulau sekitarnya berubah menjadi sejumlah kabupaten. Sekarang ini ada sepuluh kabupaten/kota di Provinisi Maluku Utara. Di pulau Halmahera sendiri ada empat kabuptaen (Halmahera Barat, Halmahera Timur, Halmahera Tengah dan Halmahera Utara). Perubahan ini memberi dampak pada tata-ruang publik pulau Halmahera baik secara geografis maupun secara sosial-ekonomi, sosial-politik, sosial-keagamaan dan sosial-budaya. Salah satu dampak dari perubahan tata-ruang publik di pulau Halmahera adalah perebutan batas-wilayah. Kasus yang hingga kini masih menjadi polemik baik di kalangan masyarakat maupun di kalangan elit politik lokal ialah batas-wilayah antara Kabupaten Halmahera Barat dan Kabupaten Halmahera Utara. ${ }^{3}$

Kedua, perubahan tata-ruang batas-wilayah di atas telah menyebabkan terjadinya "perang saudara" antarsesama warga masyarakat baik di Tobelo maupun di kecamatan Malifut antara tahun 1999-2001. Konflik antarwarga ini kemudian menjadi konflik antarumat beda agama, khususnya antara umat Muslim dan umat Kristen. Konflik yang pada awalnya berskala terbatas di kedua kecamatan ini kemudian meluas di seluruh wilayah pulau Halmahera dan pulau-pulau sekitarnya. ${ }^{4}$ Ketiga, setelah konflik berakhir hingga sekarang ini kita menyaksikan sedang terjadi pergeseran pola ekonomi warga masyarakat di pulau Halmahera dan pulau sekitarnya. Perlahanlahan pola ekonomi di ruang publik Halmahera bergeser dari pola ekonomi pertanian masyarakat desa (rural-society-economy) ke pola ekonomi pasar masyarakat kota (urban-societymarket-economy). Kita mencatat, misalnya, di Kabupaten Halmahera Utara sekarang ini telah beroperasi secara luas Alfamidi di Ibu Kota Kecamatan yang berdekatan dengan Ibu Kota Kabupaten Halmahera Utara. Keempat, sedang tumbuh ekonomi pertambangan di pulau Halmahera dan pulau-pulau sekitarnya berbarengan dengan pola ekonomi pasar tadi. Perubahan ini bukan saja berdampak bagi kerusakan lingkungan seperti terjadi di pulau Gebe ${ }^{5}$; melainkan juga tersingkirnya masyarakat lokal dari tanah tempat tinggal mereka serta terjadinya konflik antar-

\footnotetext{
1 James Haire, Teologi Kontekstual Dan Henrik van Dijken Dalam Ziarah Dalam Misi: Buku Penghormatan Pdt. Prof. Dr. Jan Arie Bastiaan Jongeneel, ed. Karolina Agustien Kaunang (Tomohon: UKIT Press, 2014) 284-290.

${ }^{2}$ Liliane Mojau, "Karya-Karya Sosial Zending UZV Di Halmahera", Dalam Bertumbuh Bersama Dalam Arus Zaman Yang Terus Berubah: Bunga Rampai 70 Tahun Gereja Masehi Injili Di Halmahera, ed. Liliane Mojau, Jerizal Petrus, and Sirayandris J. Botara (Jakarta-Tobelo: BPK Gunung Mulia dan Universitas Halamahera-BPHS GMIH, 2019), 92-99.

${ }^{3}$ Dafrin Muksin, "Dampak Sengketa Wilayah Kabupaten Halmahera Barat Dan Halmahera Utara Terhadap Pengelolaan Pemerintahan Di Desa Bobaneigo," AL-IMARAH: Jurnal Pemerintahan dan Politik Islam 6, no. 42 (2021): 143-155.

${ }^{4}$ Christopher R. Duncan, Violence and Vengeance : Religious Conflict and Its Aftermath in Eastern Indonesia (Ithaca and London: Cornell Universty Press, 2013), 47-68.

${ }^{5}$ Abdullah Naim, dkk (eds.), Pulau Kecil Indonesia, Tanah Air Tambang: Laporan Penghancuran Sekujur Tubuh Pulau Kecil Indonesia oleh Tambang Miniral dan Batu Bara, (Jakarta: Jaringan Advokasi Tambang, 2019), 25-40.
} 
warga masyarkat dan konflik antara warga masyarakat dengan pemerintah desa seperti terjadi di desa Mamoji Kecamatan Loloda Utara. ${ }^{6}$

Dalam konteks ruang publik seperti di atas inilah Sinode GMIH bergumul dan melaksanakan panggilan serta fungsi sosialnya secara teologis. Dalam rentang sejarah sosial otonomi daerah 2002-2017, Sinode GMIH telah melakukan empat kali Sidang Sinode Gereja Masehi Injili di Halmahera (Sidang Sinode GMIH) untuk menggumuli secara teologis dan eklesiologis fungsi sosial Sinode GMIH dalam konteks ruang publik Halmahera di era otonomi daerah. Pertanyaan untuk dijawab dalam kajian ini ialah bagaimana Sinode GMIH memahami fungsi sosialnya secara teologis dan eklesiologis seperti tertuang dalam dokumen-dokumen gerejawi GMIH hasil Sidang Sinode GMIH periode pelayanan 2002-2017? Apakah fungsi-fungsi sosial Sinode GMIH itu telah memiliki dasar teologis yang memadai dan mendalam? Selama ini telah ada beberapa kajian teologis tentang ruang publik Halmahera pascakekerasan sosial dan era otonomi daerah. Ruddy Tindage pernah mengkaji upaya-upaya rekonsiliasi sosial yang berlangsung antara tahun 2000-2001. Dalam kajiannya ia memperlihatkan bahwa para pemimpin Sinode GMIH cukup memainkan peranan penting untuk mendorong proses-proses rekonsiliasi. Para pemimpin baik di lingkup Jemaat maupun di lingkup Sinode GMIH telah mengambil banyak inisiatif untuk bekerjasama dengan tokoh-tokoh adat dalam mengupayakan proses-proses mediasi untuk mewujudkan rung publik Halmahera yang damai. Dalam kajian Tindage juga menyebutkan bahwa pendekatan kultural melalui gagasan rumah adat Halmahera-khusus di Halmahera Utara yang disebut: hibualamo — telah memerankan peran simbolik yang signifikan menumbuhkan ikatanemosional untuk memulihkan relasi yang harmonis dan damai antarwarga masyarakat Halmahera Utara. Oleh karena itu, demikian Tindage, adalah tugas Gereja berkewajiban untuk terus memelihara perdamaian itu baik secara institusional maupun perorangan untuk menghadirakan damai sejahtera di ruang publik Halmahera umumnya dan Halmahera Utara khususnya. ${ }^{7}$

Frederick R. Putjutju mengkaji konsep teologis rekonsiliasi sosial dengan mendialog budaya esa moi di kalangan subetnis Tobaru di Halmahera Barat. Kajiannya memperlihatkan bahwa psiko-linguistik budaya esa moi telah menjadi daya pembangkit kesasadaran rekonsiliatif antara umat Muslim dan Kristen di Kecamatan Ibu-Halmahera Barat. Berdasarkan temuannya itu maka ia berpendapat bahwa konsep teologi perdamian esa moi dapat menjadi model untuk merawat perdamaian abadi dalam masyarakat majemuk di Halmahera. ${ }^{8}$

Sefnat Hontong, dalam kajiannya tentang makna pusara para korban di kalangan Kristen, di Jemaat Duma Galela menunjukkan bahwa ingatan keluarga para korban dapat menjadi sumber budaya damai pascakonflik. la menunjukan bahwa ingatan keluarga korban sebagaimana terungkap dalam psiko-linguistik kosakata bahasa Galelaa: dodara, dapat menjadi pintu masuk mengembangkan wacana teologis tentang perdamaian. Bukan saja menjadi wacana teologis melainkan dapat menjadai praxis hidup berdamai dengan mereka pernah melukai dan membunuh para korban. Menurut Hontong bahwa melalui konsep-kultural dodara di kalangan orang Galela dapat menjadi konsepti teologis tentang ingatan emansipatoris di kalangan keluarga para korban tentang makna kasih Tuhan yang merangkul antarpihak yang pernah saling melukai dan saling membunuh. Oleh karena itu, demikian Hontong, kosakata dodara memiliki daya psikolinguistik secara teologis untuk membangun budaya damai dalam ruang publik Halmahera pascakonflik. ${ }^{9}$

\footnotetext{
${ }^{6}$ Tentang kasus-kasus ini lihat, misalnya, Surya Saluang, Didi Novrian, Risman Buamona dan Meifita Handayani, Perampasan Ruang Hidup: Cerita Orang Halmahera (Yogyakarta: Tanah Air Beta, 2014) dan Bonny Datty, Politik Pertambangan: Konflik Penambangan Pasir Besi, Konflik Vertikal, Perbedaan Persepsi dan Studi tentang Peta Konflik Pertambangan Pasir Besi di Desa Mamojio Loloda Utara (Tesis Magister Ilmu Politik pada Fakultas Ilmu Sosial dan Ilmu Politik Universitas Arlangga Surabaya, 2015).

${ }^{7}$ Ruddy Tindage, Damai Yang Sejati: Rekonsiliasi Di Tobelo-Kajian Teologi Dan Komunikasi (Jakarta: YAKOMA-PGI, 2006), 64-111.

${ }^{8}$ Frederick R. Putjutuju, Esa Moi: Teologi Rekonsiliatif Di Tengah Kemajemukan Halmahera (Yogyakarta: : Lintang, 2012), 73-132.

${ }_{9}^{9}$ Sefnat Hontong, "Eksistensi Pusara Dodara: Upaya Hermeneutik Etis-Teologis Bagi Pengembangan Budaya Damai Di Halmahera" (Yogykarta-Tobelo: Kanisius dan Universitas Halmahera, 2012) 65-145.
} 
Berdasarkan inisiatif para pendeta Sinode GMIH, baik di lingkup Jemaat maupun Sinode $\mathrm{GMIH}$, serta perkembangan pemikiran teologis di atas, Mary Christine Haire menilai bahwa para pendeta Sinode GMIH telah banyak mengambil insiatif untuk mewujudkan ruang publik Halmahera yang damai di masa-masa sulit ketika terjadi kekerasan sosial masif di pulau Halmahera seperti diuraikan di atas. la bahkan menyebut para pendeta Sinode GMIH telah menjadi "duta perdamaian" bagi terciptanya ruang publik Halmahera yang damai. ${ }^{10}$ Berbeda dengan kajian teologis Demianus Nataniel memberi kesan bahwa selama konflik para pemimpin Kristen di Maluku Utara (baca: pendeta Sinode GMIH) hanya menoleransi secara teologis angkat senjata di tengah-tengah situasi pada saat itu. ${ }^{11}$

Kajian Demianus Nataniel ini perlu dilengkapi dengan data-data yang lebih luas. Jika kita berbicara alasan-alasan teologis keterlibatan para pendeta dalam ruang publik Halmahera, maka kita tidak bisa mengabaikan dokumen-dokumen teologis dan gerejawi Sinode GMIH selama periode pelayanan 2002-2017. Karena pada persidangan-persidangan tersebutlah Sinode GMIH dan para pendetanya serta para penatua dan diaken menggumuli secara teologis ruang publik Halmahera seiring dengan pembentukan otonomi daerah dan pengelolaan otonomi daerah secara ekonomi dan politik. Penulis pernah melakukan suatu eksperimen pengembangan teologi publik kehalmaheraan. Dalam eksperimen tersebut penulis memetakan kelima kegelisahan teologis di ruang publik Halmahera setelah otonomi daerah, yaitu: (a) kebutuhan pendidikan yang bermutu; (b) kesejahteraan ekonomi yang berkeadilan sosial: (c) keadilan hukum yang berpihak pada hak-hak rakyat; (d) membangun komunitas sosial multicultural; (e) hak-hak atas tanah dan krisis ekologi. ${ }^{12}$

Kajian teologis tersebut belum meneliti secara khusus tentang isi dokumen-dokumen gerejawi Sinode GMIH secara teologis dan eklesiologis di era otonomi daerah. Dalam kajian eksperimental penulis tentang teologi publik kontekstual di ruang publik Halmahera telah memberi perhatian secara teologis tentang keprihatinan ruang publik, seperti membangun masyarakat secara adil dan damai. Tetapi penulis juga belum memberi perhatian khusus dan/atau mendialogkan isi teologis dan eklesiologis dokumen-dokumen gerejawi Sinode GMIH. Maka kajian ini merupakan kelanjutan sekaligus melengkapi kajian penulis sebelumnya itu.

Ada tiga konteks pelayanan Sinode masa kini membuat kajian ini penting. Pertama, proses demokrasi lokal di era otonomi daerah, di pulau Halmahera dan pulau-pulau sekitarnya seringkali membawa dampak pada terbelahnya warga Jemaat Sinode GMIH, yang berpotensi memperkuat konflik internal GMIH yang sudah berlangsung sejak 2013 lalu. Kedua, perkembangan ekonomi pasar yang disertai oleh masifnya ekonomi pertambangan yang tidak saja menyebabkan terciptanya kemiskinan struktural melainkan juga berdampak pada kerusakan ekologis. Ketiga, GMIH adalah salah satu lembaga keagamaan di Indonesia yang memiliki tanggungjawab sosial bersama gereja lain, dan agama lainnya di Indonesia, untuk menciptakan ruang publik keindonesiaan yang adil, damai, dan harmonis, berdasarkan Pancasila dan UUD 1945. Maka, melalui kajian ini, diharapkan Sinode GMIH dapat melakukan evaluasi kritis-konstruktif terhadap praxis teologi publiknya bagi upaya mendukung fungsi sosialnya yang relevan dan signifikan terkait tantangan-tantangan pelayanan kontekstual di era otonomi daerah. Selain itu, Sinode GMIH juga dapat memberi sumbangan terhadap upaya bersama Gereja-gereja di Indonesia untuk membangun ruang publik masyarakat majemuk Indonesia, yang tidak jarang juga selalu diwarnai oleh kekerasan sosial baik atas nama agama maupun etnisitas. Pendek kata, kajian ini selain merupakan evaluasi internal Sinode GMIH, juga dapat merupakan sumbangan Sinode GMIH

${ }^{10}$ Mary Christine Haire, "Sosiologi, Pekerjaan Sosial Dan Peranan Pendeta GMIH" Bertumbuh Bersama Dalam Arus Zaman Yang Terus Berubah, ed. Liliane Mojau, Jerizal Petrus, and Sirayandris J. Botara (Jakarta-Tobelo: BPK Gunung Mulia dan Universitas Halamahera-BPHS GMIH, 2019), 109-111.

${ }^{11}$ Demianus Nataniel, "Paulus Dalam Konflik Antarumat Beragama: Membaca Konflik Di Maluku Utara Berdasarkan Sikap Nasionalisme Paulus," GEMA TEOLOGIKA: Jurnal Teologi Kontekstual dan Filsafat Keilahian 4, no. 2 (2019): 195.

12 Julianus Mojau, Ke Arah Pengembangan Teologi Publik Ke-Halmahera-an", Dalam Menggereja Dalam Konteks Halmahera: 65 Tahun Dan Purnatugas Pdt. Arkhipus Dujubasa, ed. Imelda Kahiking, Stenling F. Korois, and Marton Tasiringan (Tobelo: Fakultas Teologi Universitas Halmahera, 2020) 173-183. 
dalam rangka upaya bersama warga masyarakat Indonesia untuk membangun ruang publik keindonesia yang adil, rukun, damai dan harmonis berdasarkan Pancasila dan UUD 1945.

Di sini fungsi sosial Gereja yang menggunakan teori komunikasi publik rasional Jürgen Habermas seperti ditekankan oleh Ricardo F. Nanuru ${ }^{13}$ dan sifat advokatif dan intererleigius teologi publik Asia seperti ditekankan oleh Felix Wilfred ${ }^{14}$ dan Feliciano V. Cariňo ${ }^{15}$ akan menjadi kerangka teoritis dalam menganalisis isi teologis dokumen-dokumen gerejawi Sinode GMIH. Maka tujuan dari kajian ini ialah mengkaji secara kritis-konstruktif praxis teologi Sinode GMIH yang tertuang dalam keputusan-keputusan sidang-sidang Sinode GMIH selama periode pelayanan 2002-2017 dari perspektif teori fungsi sosial Gereja Habermasian seperti ditekankan oleh Ricardo F. Nanuru dan teologi publik advokatif Feliciano V. Cariňo dan teologi publik advokatif interreligius Felix Wilfred.

\section{METODE}

Kajian dalam tulisan ini menggunakan metode penelitian kualitatif jenis penelitian kepustakaan (library-research) tentang dokumen-dokumen gerejawi Sinode GMIH selama periode pelayanan 2002-2017. Menurut Dèdè Oetomo, metode penelitian kualitatif tipe ini dapat diterapkan pada analisis dokumen-dokumen tertulis sebagai objek kajian. ${ }^{16}$ Maka data primer dalam kajian ini adalah keputusan Sidang Sinode XXV (2002) sampai dengan keputusan Sidang Sinode XXVIII (2017). Sumber primer lain adalah keputusan-keputusan Rapat Kerja dan Sidang Majelis Sinode Tahunan Sinode GMIH yang berlangsung di antara Sidang Sinode XXV dan Sidang Sinode XXVIII. Sumber-sumber primer ini akan didukung oleh sumber sekunder untuk mendukung analis konteks berupa buku-buku sejarah, sosial dan ekonomi. Hal ini penting karena analisis teologi publik selalu bersifat interdisipliner. ${ }^{17}$

Sumber-sumber (baik primer maupun sekunder) sebagai objek kajian akan dianalisis makna teologis sosialnya ${ }^{18}$ untuk mengidentifikasi tipe wacana dan praxis teologi dan hidup menggereja yang dihasilkan oleh persidangan-persidangan Sinode GMIH. Di sini teori fungsi sosial Gereja Habermasian seperti ditekankan oleh Nanuru dan sifat advokatif dan intereligius teologi publik seperti ditekankan oleh Wilfred dan Cariňo memainkan peranan penting dalam mengidentifikasi dan menganalisis tipe praxis teologi Sinode GMIH dalam dikumen-dokumen gerejawinya selama kurun waktu 2002-2017.

\section{Hasil dan Pembahasan}

Dari penelitian terhadap dokumen-dokumen gerejawi Sinode GMIH selama periode persidangan Sinode 2002-2017 maka ditemukan praxis teologi publik Sinode GMIH sebagai berikut:

\section{Merawat Semangat dan Komitmen Iman Sosial Rekonsiliatif}

Kita telah mencatat sebelumnya bahwa pembentukan kabupaten/kota di pulau Halmahera berdampak pada perebutan batas wilayah. Konflik batas wilayah tersebut telah menyulut konflik antaretinis dan antarumat beda agama. Pembelahan sosial berdasarkan latar belakang etnisitas dan agama itu kemudian membakar sentimen emosional etnisitas dan keagamaan yang meluluhlantakkan harmoni relasi Muslim-Kristen yang terbangun beratus-ratus tahun itu. Relasi IslamKristen yang sebelumnya begitu harmonis tiba-tiba menjadi lautan darah di ruang publik Halma-

\footnotetext{
${ }^{13}$ Ricardo F. Nanuru, "Fungsi Sosial Gereja Menurut Konsep Rasionalitas Jürgen Habermas", Dalam Politik Sang Guru: Buku Penghormatan Pdt (Em.) Hans Alexander Annu, M,Th, ed. Anselmus Puasa, Arkipus Djurubasa, and Broery D.P. Tjaya (Yogyakarta: Kanisius, 2014) 187-233.

${ }^{14}$ Felix Wilfred, Asian Public Theology: Critical Concerns in Challenging Times (Delhi: ISPCK, 2010), xii-xxii.

${ }^{15}$ Feliciano V. Cariňo, Asian Politics and Ecumenical Vision: Selected Writings Of, ed. Bnd. Philip L., Wickeri, and Mariana True (Hong Kong: CCA, 2013), 18-26 .

${ }^{16}$ Jeniffer Pelupessy Wowor, "Partisipasi Pendidikan Kristiani Di Ruang Publik Dalam Menunjang Deradikalisasi," Kurios 7, no. 1 (2021): 108.

${ }_{17}^{17}$ Wilfred, Asian Public Theology: Critical Concerns in Challenging Times, xxii.

${ }^{18}$ Sugiyono, Metode Penelitian Kuantitatif-Kualitatif Dan R \& D (Bandung: Alfabeta, 2009), 8-9.
} 
hera. Militasi religius yang seharusnya memuliakan Allah dengan menjunjung tinggi har-kat dan martabat manusia telah berubah menjadi pelikan militasi peperangan saling meniadakan tanpa mengenal hubungan keluarga. ${ }^{19}$ Farsijana Adeney-Risakotta memperlihatkan bahwa kon-flik sosial yang bernunasa SARA di ruang publik Halmahera di penghujung rezim Orde Baru tersebut berakar dalam penguatan politik identitas yang dimainkan elit politik nasional di Indonesia menyertai runtuhnya kekuasaan hegemonik rezim Orde Baru. ${ }^{20}$

Tindage memperlihatkan bahwa para pendeta Sinode GMIH bersama-sama dengan para tokoh adatlah yang telah menginisiasi pertemuan perdamaian antara pihak Islam dan Kristen. Langkah konkret tersebut membuahkan deklarasi damai tepat pada 19 April 2001. ${ }^{21}$ Laporan Majelis Pekerja Sinode Sinode Gereja Masehi Injili di Halmahera (MPS Sinode GMIH) periode pelayanan 1997-2002 pada Sidang Sinode XXV (2002) di Jemaat Ikhtus Wari Kecamatan Tobelo yang masih dibayang-bayangi oleh beberapa peristiwa berdarah di sebagian wilayah di Halmahera mencatat "ajakan pastoral" kepada para peserta Sidang Sinode XXV agar pokok rekonsiliasi menjadi salah satu agenda mendesak pada persidangan Sinode GMIH tersebut. ${ }^{22}$ Ajakan pastoral tersebut mendapat sambutan positif dari para peserta persidangan, sehingga menjadi pokok percakapan serius persidangan yang menghasilkan visi dan misi teologis Sinode GMIH untuk terus membangun semangat dan komitmen sosial iman rekonsiliatif. Sambil merujuk kepada sejumlah teks Alkitab (Kej. 12:3; Yes. 16-17; Maz. 34:15; Mat. 5:46-47; Gal. 3:14), Sidang Sinode XXV menekankan bahwa upaya menyemaikan dan merawat semangat dan komitmen iman sosial rekonsiliatif adalah panggilan Sinode GMIH untuk menjadi berkat bagi semua orang. Visi dan misi ini sangat jelas tertuang dalam pesan dan rekomendasi Sidang Sinode XXV. Dalam pesan dan rekomendasi ditegaskan bahwa upaya merawat semangat dan komitmen iman sosial rekonsiliatif adalah panggilan sosial GMIH sebagaimana diteladankan Yesus Kristus. ${ }^{23}$

Sidang Sinode XXVI (2007) di Jemaat Tiga Saudara-Ibu Halmahera Barat mendorong agar semangat dan komitmen iman sosial rekonsiliatif menjadi pola hidup para pendeta dan warga Sinode GMIH. Pola hidup ini tak terpisahkan dari kemandirian mengelola kehidupan ekonomi dan kemandirian politis di tengah-tengah politik otonomi daerah yang tidak jarang membawa gesekan dan kekerasan sosial di akar-rumput (grass-root). ${ }^{24}$ Dalam kesadaran inilah maka peran edukasional Fakultas Teologi Universiatas Halmahera (FT-Uniera) didorong untuk mengembangkan teologi kontekstual dengan menjadikan teologi perdamaian sebagai pengorganisasian kerangka epistemik berteologi publik kontekstual dalam konteks pelayanan Sinode GMIH pada saat revisi kurikulum tahun 2012. ${ }^{25}$ Memasuki pertengahan tahun 2013, berlangsunglah pemilihan Gubernur dan Wakil Gubernur di Provinsi Maluku Utara. Tak terhindarkan bahwa pesta demokrasi lokal ini telah menyeret GMIH ke dalam konflik internal. Seperti diikhtiarkan pada setiap persidangan Sinode GMIH antara 2002-2012 bahwa otonomi daerah perlu dikelola dengan bijak agar ruang publik Halmahera tetap demokratis dan damai. Karena, dari catatan dokumen persidangan, sebagaimana dilaporkan oleh MPS/BPHS GMIH pada setiap Sidang Sinode, bahwa pesta demokrasi di era otonomi telah menyumbang kepada pembelahan Jemaat dalam Sinode GMIH. ${ }^{26}$

Dari data di atas terlihat bahwa merawat semangat dan komitmen sosial rekonsiliatif tidak pernah akan berakhir karena dua hal. Pertama, proses demokratisasi politik di pulau Halmahera masih belum matang sehingga tidak jarang melahirkan letupan-letupan kekerasan sosial di dalam ruang publik di Halmahera. Kedua, ketidakmatangan proses demokrasi politik telah memberi

\footnotetext{
${ }^{19}$ Duncan, Violence and Vengeance : Religious Conflict and Its Aftermath in Eastern Indonesia.

${ }^{20}$ Farsijana Adeney-Risakotta, "Politics, Ritual and Identity in Indonesia: An Moluccan History of Religion and Social Conflic" (Radbound Universiteit Nijmegen, 2005) 189-227, 346-347.

${ }^{21}$ Tindage, Damai Yang Sejati,64-89.

${ }^{22}$ Keputusan Sidang Sinode XXV GMIH Wari, 01-06 Juni (2002) 15-16, 26, 112.

${ }^{23}$ Keputusan Sidang Sinode XXV (2002), 112.

${ }^{24}$ Keputusan-Keputusan Sidang Sinode XXVI (2007), 189.

${ }^{25}$ Kurikulum Fakultas Teologi Universitas Halmahera 2012.

${ }^{26}$ Ini sangat dalam setiap keputusan sidang sinode selama 2002-2012.
} 
dampak pada perpecahan di sejumlah jemaat dalam Sinode GMIH. Puncak dari hal ini adalah dualisme kepengurusan Sinode GMIH pada pertengahan tahun 2013. Berkelindannya ketidakdewasaan berpolitik para elit lokal secara demokratis dengan ketidakmatangan warga masyarakat di tengah-tengah "euforia demokratisasi sosial" di era otonomi daerah ini telah membuat $\mathrm{GMIH}$ terus menerus menggemakan pentingnya upaya menyemai dan merawat semangat dan komitmen iman sosial rekonsiliastif hingga terciptanya kedewasaan berdemokrasi. Kita dapat membaca ini dalam setiap keputusan Rapat-Rapat Kerja Tahun 2002-2007 (Rakerta 2002-2007) dan Sidang Majelis Sinode Tahunan Sinode GMIH periode 2007-2016 (SMST Sinode GMIH 2007-2016). Pada rapat-rapat kerja ini selalu ditekankan perlunya kedewasaan warga jemaat dan warga masyarakat dalam berdemokrasi sehingga perdamaian abadi di pulau Halmahera dan pulau-pulau sekitarnya dapat menjadi pola hidup sosial warga masyarakat Halmahera. ${ }^{27}$

Dapat dikatakan, bahwa merawat semangat dan komitmen iman sosial rekonsiliatif sebagai praxis hidup menggereja GMIH di tengah-tengah tantangan konflik internal merupakan tantangan tersendiri. Sekalipun harus dibebani oleh tantangan internal, namun GMIH tidak pernah pernah lelah untuk menyemaikan semangat dan komitmen iman sosial rekonsiliatif. Sidang Sinode XXVIII (2017) di Bali, Halmahera Timur, memutuskan untuk melanjutkan usaha-usaha rekonsiliasi internal. Hal ini sangat jelas dalam pesan dan rekomendasi Sidang Sinode XXVIII (2017). ${ }^{28}$ Ini adalah salib Sinode GMIH yang harus dipikul oleh Sinode GMIH sendiri untuk mewujudkan identitas eklesialnya sebagai tubuh sosial Kristus yang rekonsiliatif. Sejatinya, jalan salib ini bukanlah hal yang sulit bagi Sinode GMIH sebagai tubuh Kristus untuk menjalaninya. Karena Sinode GMIH, sebagai tubuh Kristus, sejatinya memiliki "daya penyembuhan diri sendiri", yaitu iman kepada pengampunan Allah yang diaktakan dalam liturgi Sinode GMIH, dan setiap minggu didaraskan secara liturgis baik melalui doa maupun pujian. ${ }^{29}$ Hanya dengan hati yang sabar dan pikiran yang jernih menalarlah yang akan mampu melihat, merasakan, dan menyaksikan tarian perdamaian yang akan diragakan oleh Sinode GMIH pada waktunya. Sejatinya, hal ini tidaklah mustahil karena semangat dan komitmen sosial rekonsilitatif itu memiliki basis teologis kultural dalam budaya orang-orang Halmahera. Misalnya, basis teologis kultural itu dapat ditemukan dalam budaya esa moi di kalangan subetnis Tobaru, seperti diperlihatkan oleh Putjutju yang telah disinggung dalam uraian sebelumnya. Atau, seperti diperlihatkan oleh Hontong tentang gagasan teologi dodara ketika memaknai makam para korban di Duma-Galela sebagai ingatan untuk menumbuhkan sumber budaya damai dalam ruang publik kehalmaheraan pascakekerasan sosial. Penulis sendiri lebih mengakarkan teologi publik kontekstual di ruang publik Halmahera dengan mendialog secara teologis gagasan psiko-linguistik kata bertenaga diai dan tiai. ${ }^{30}$

\section{Merawat Semangat dan Komitmen Iman Sosial Ekonomi}

Pada masa Zending, salah satu fungsi sosial Zending yang mendapat perhatian para Zendeling ialah mengupayakan kemandirian dana di lapangan Zending dengan jalan membuka lahan pertanian yang diisi dengan perkebunan kelapa. Memang usaha pelayanan sosial ini tidak selalu gampang. Ada banyak tantangan baik itu datang dari pihak penduduk Halmahera maupun dari pihak para Zendeling sendiri. Tantangan-tantangan itu tidak membuat para Zendeling berhenti berinisiatif. Ketika Zending memandirikan Sinode GMIH menjadi Gereja mandiri pada 6 Juni 1949 pelayanan sosial ini telah menyebar luas di wilayah-wilayah pelayanan Zending. ${ }^{31}$ Antara tahun 1970-1980-an bidang pelayanan sosial ini mengambil wujud konkret Traning Center (TC) yang berdiri di atas lahan Wari-Wosia Klapper Orderneming (WKO) di desa Wosia yang sangat

\footnotetext{
${ }^{27}$ Lihat Keputusan-Keputusan Rapat-Rapat Kerja pada periode ini.

${ }^{28}$ Keputusan Sidang Sinode XXVIII (2017), 138-139.

${ }^{29}$ Liturgi GMIH 2017 (Bentuk I-IV).

${ }^{30}$ Julianus Mojau, "GMIH Itu Komunitas Iman Diai", Dalam Bertumbuh Bersama Dalam Arus Zaman Yang Terus Berubah, , 268-271.

${ }^{31}$ M.Th. Magany, Bahtera Injil Di Halmahera (Tobelo: GMIH, 1984), 286-295.
} 
luas. ${ }^{32}$ Pada tahun 1990-an, setelah Sidang Sinode GMIH tahun 1992, TC GMIH ini mentransformasi diri menjadi Pusat Pengkajian dan Pelatihan Pengembangan Pembangunan Pedesaan (PPLPP) dalam naungan Yayasan Saro Nifero (SANRO). Seiringan perkembangan zaman tahun 1990-an lembaga pelayanan sosial GMIH melatih para petani dan masyarakat desa di pulau Halmahera dan pulau-pulau sekitarnya baik dalam bidang pertanian, pertukangan maupun pengelolaan keuangan dalam bentuk Credit Union (CU) tanpa membedakan latar belakang budaya dan agama. ${ }^{33}$

Sidang Sinode XXV (2002) mengamanatkan agar Sinode GMIH perlu mengembangkan pelayanan sosial ekonomi darurat yang mengambil bentuk pelayanan sosial-ekonomi lintas agama. Pelayanan sosial ekonomi ini dipahami sebagai upaya mengintegrasikan dialog teologis dan dialog karya. ${ }^{34}$ Ketua Umum Majelis Perkerja Sinode GMIH (MPS GMIH) periode 2002-2007 dalam arahan pastoralnya pada Rapat Kerja Tahun 2004 mengingatkan para peserta rapat kerja agar tetap memberi perhatian pada pemulihan sosial ekonomi lintas agama ini. Sambil merujuk pada tema Rakerta 2004 "Carilah Tuhan maka kamu akan hidup" (Am. 5:6a) dan kesaksian Alkitab Injil Yohanes 10 dan 14:6, beliau mengajak peserta memberi perhatian serius pada misi Sinode GMIH ke luar, di tengah-tengah persoalan nyata, baik di ruang publik global maupun di ruang publik Halmahera, dengan terus mengupayakan pelaksanaan program-program restorasiekonomi lintas agama yang sudah berlangsung antara komunitas iman Muslim dan Kristen di Jailolo dan Tobelo. ${ }^{35}$

Sidang Sinode XXVI (2007) dan Sidang Sinode XXVIII (2017) memilih Badan Usaha Milik Gereja (BUMG) dan Badan Usaha Miliki Jemaat (BUMJ) sebagai format pelayanan sosialekonomi dalam Sinode GMIH. ${ }^{36}$ Pergeseran ini dimaksudkan agar perlahan-lahan pelayanan sosial-ekonomi darurat model diakonia-karitatif dapat ditinggalkan. Maka periode pelayanan Sinode GMIH 2007-2017 lebih banyak informasi dan wacana tentang diakonia transformatif dalam persidangan-persidangan Sinode GMIH. Selain itu Sinode GMIH juga menyertakan sejumlah staf di lingkup sinode untuk mengikuti sejumlah kegiatan penyadaran pengembangan diakonia transformatif yang diselenggarakan baik melalui kemitraan dengan KerkinactieProtestantse Kerk in Nederland (Kerkinactie; PKN) maupun dalam kemitraan dengan Evangelical Mission in Solodarity (EMS) di Jerman. Bahkan telah dibentuk Bidang Diakonia Transformatif dalam lingkup Sinode GMIH pada masa pelayanan 2012-2017. ${ }^{37}$ Sejatinya, semangat dan komitmen iman sosial ekonomi berdasarkan gagasan diakonia transformatif ini telah disemaikan sejak Sidang Sinode XXV (2002). ${ }^{38}$

Dari uraian di atas kita dapat menyimpulkan bahwa perlahan-lahan Sinode GMIH mulai menggeser pelayanan sosial diakonal di bidang ekonomi untuk memasuki pola ekonomi masyarakat urban. Pergeseran dari pola pelayanan sosial-ekonomi berbasis pertanian masyarakat desa (rural-society) ke pola pelayanan sosial masyarakat urban (urban-society) mengandalkan mekanisme ekonomi pasar. Persgeseran ini menyebabkan tidak ada lagi inisiatif dan terobosan baru pembukaan lahan pertanian dan perkebunan seperti pada tahun 1970-an sampai dengan 1990-an. Bahkan mengabaikan lahan-lahan produktif Sinode GMIH seperti di Talaga Paca Tobelo Timur Kabupaten Halmahera Utara. Juga gaung perkebunan Jemaat sudah meredup.

\footnotetext{
${ }^{32}$ Liliane Mojau, "Karya-Karya Sosial Zending UZV di Halmahera", dalam Bertumbuh Bersama dalam Arus Zaman yang Terus Berubah., 93-94. Juga Julianus Mojau, "Partisipasi GMIH dalam Pembangunan Daerah: Kemandirian adalah Pilar Partisipasi Gereja dalam Pembangunan Daerah di Era Otonomi Daerah", dalam Teologi Politik: Panggilan Gereja di Bidang Politik Pascaorde Baru, eds. John Campbell-Nelson, Julianus Mojau dan Zakaria J. Ngelow (Makassar: Oase Intim, 2013), 250-251.

${ }^{33}$ Dokumen Program Pengembangan Usaha Tani Terpadu Kecamatan Kao, Tobelo dan Galela, Kabupaten Maluku Utara, Provinsi Maluku, Indonesia-FADO-SANRO 1995.

${ }^{34}$ Kurikulum Fakultas Teologi Universitas Halmahera 2012.

${ }^{35}$ Keputusan Rapat Kerja III GMIH (2004), 6

${ }^{36}$ Keputusan Sidang Sinode XXVI (2007), Sidang Sinode XXVII (2012) dan Sidang Sinode XXVII (2017).

${ }^{37}$ Laporan BPHS GMIH Periode 2012-2017 pada SMS I GMIH tahun 2013, khusus Pembentukan BidangBidang Pelayanan.

${ }^{38}$ Keputusan Sidang Sinode XXV GMIH, Wari, 01-06 Juni 2002, 30
} 
Pergeseran ini disebabkan oleh dua hal. Pertama, era otonomi daerah telah menciptakan suatu pergeseran pola pikir warga jemaat dan warga masyarakat di lingkup pelayanan Sinode GMIH yang lebih berorientasi pada pola hidup masyarakat kota yang alpa memberi perhatian pada ekonomi pertanian. Kedua, perkembangan kota ini telah mengubah asset ekonomi Sinode GMIH dan pusat pemberdayaan ekonomi berbasis pertanian terpadu di Tobelo menjadi lahan pemukiman. $^{39}$

Sinode GMIH, ke depan, sebaiknya menghidupkan kembali semangat dan komitmen iman sosial-ekonomi dalam bentuk gerakan pemberdayaan ekonomi rakyat berbasis pertanian agar Sinode GMIH dapat memediasi potensi ekonomi masyarakat lokal dan warga jemaatnya agar tidak terperangkap dalam kemiskinan struktural di tengah-tengah perkembangan ekonomi lokal yang cenderung kapitalistik di era otonomi daerah ini. Pelaksanaan fungsi sosial ini akan memampukan Sinode GMIH dapat memfasilitasi ekonomi kerakyatan mendialog dan memediasi ekonomi global neo-liberalisme yang terus mengepakkan sayap melalui ekonomi pasar bebas pertambangan di era otonomi ini. ${ }^{40}$ Fungsi sosial ini mendesak mengingat kecenderungan arah dan pilar ekonomi nasional Indonesia terus berada dalam pusaran pola ekonomi global yang lebih mengandalkan sistem ekonomi moneter dan kapitalisme yang telah dimulai sejak zaman kolonial dan menguat pada zaman Indonesia merdeka pada zaman Orde Baru. Seperti diperlihatkan oleh para analisis nalar ekonomi nasional Indonesia bahwa selama ini sistem ekonomi Indonesia cenderung kepada sistem ekonomi neo-lib yang menciptakan kemiskinan struktural dan kesejangan sosial. ${ }^{41}$

Pada SMST 2019 di Soatabaru, Galela, Sinode GMIH mengambil inisiatif lagi untuk menghidupkan kembali gagasan diakonia transformatif. Oleh karena itu, SMST ini diawali dengan percakapan teologis tentang kewirausahaan dalam bentuk study meeting. Kita berhadap bahwa insentif menghidupkan kembali diakonia transformatif ini dapat mewujud dalam programprogram konkret terukur bagi gerakan pemberdayaan ekonomi umat/warga Jemaat dan warga masyarakat di tengah-tengah perkembangan dan perubahan sosial ekonomi di era otonomi ini.

Dalam diakonia transformatif Sinode GMIH dapat belajar dari pengalamannya mengelola TC WKO antara tahun 1970-an sampai 1980-an. Sinode GMIH juga dapat belajar dari pengembangan industri pertaniaan Yayasan Trukajaya Salatiga, Gereja Kristen Jawa. Sekalipun berada di tengah-tengah masyarakat urban dan dikepung oleh industri pertanian modern ala ekonomi kapitalisme, namun mereka tidak surut semangat dan komitmen iman sosial-ekonomi berbasis ekonomi pertanian dengan menghidupkan potensi ekonomi lokal dan menciptakan jejaring pasar sendiri. Dengan demikian mereka tidak didikte oleh ekonomi pasar neo-liberalisme. ${ }^{42}$ Langkah konkret seperti ini rasanya sangat relevan bagi pelaksanaan panggilan dan fungsi sosialekonomi Sinode GMIH di ruang publik Halmahera di mana sebagian besar warga jemaat dan warga masyarakatnya masih bertumpu pada ekonomi pertanian. Mengingat konteks ruang publik Halmahera selain majemuk juga pernah punya pengalaman kekerasan sosial antarumat beda agama maka semangat iman ekonomi kewirausaan dan pemberdayaan lintas agama yang pernah dilakukan pada situasi darurat (2002-2007) perlu menjadi bagian dari kesadaran iman membangun laboratorium ekonomi pertanian lintas agama. Dengan mengembangkan praxis advokasi profetik teologi publik seperti ini Sinode GMIH sungguh-sungguh sedang meragakan identitas eklesialnya sebagai tubuh sosial-ekonomi Kristus di tengah-tengah arus ekonomi global yang neo-kapitalisme itu. ${ }^{43}$ Peragaan identitas eklesial sosial seperti inilah Sinode GMIH dapat memerankan diakonia profetik sebagai advokasi memperjuangkan dan menegakkan keadilan sosial

\footnotetext{
${ }^{39}$ Mojau, "Karya-Karya Sosial Zending UZV Di Halmahera", Dalam Bertumbuh Bersama Dalam Arus Zaman Yang Terus Berubah, 94.

${ }^{40}$ Francis Wahono, Ekonomi Politik Daulat Rakyat Indonesia: Pancasila Sebagai Acuan Paradigma (Jakarta: Kompas, 2020), 60-70, 243-257.

${ }^{41}$ Jan Luiten van Zanden and Daan Marks, Ekonomi Indonesia 1800-2010: Antara Drama Dan Keajaiban Pertumbuhan (Jakarta: Kompas dan KITLV-Jakarta, 2012), 430-457.

${ }^{42}$ Profil Yayasan Trukajaya Salatiga, https://trukajaya.org/i-sejarah/visi-misi/program, diakses, 24 Agustus 2021.

${ }^{43}$ Wilfred, Asian Public Theology: Critical Concerns in Challenging Times, 123-155 dan Philip L. Wickeri and Mariana True (Eds.), Asian Politics and Ecumenical Vision, 213-218.
} 
ekonomi bagi seluruh lapisan masyarakat agar semua lapisan masyarakat mengalami kepenuhan hidup di ruang publik Halmahera di era otonomi daerah. ${ }^{44}$

\section{Menyemai Semangat dan Komitmen Iman Ekologis}

Sidang Sinode XXV (2002) mendorong agar pemerintah daerah di Maluku Utara dapat mengelola dan memanfaatkan sumber daya alam (SDA) sebaik-baiknya dan seadil-adilnya bagi kesejahteraan masyarakat Maluku Utara. Selain itu Sidang Sinode XXV juga mengingatkan agar penatalayanan SDA itu tidak bersifat sewenang-wenang dan eksploitatif. Himbauan ini bukan saja kepada pemerintah melainkan juga kepada warga jemaat dalam Sinode GMIH sendiri. ${ }^{45}$ Maka dari itu, pesan dan rekomendasi Rakerta 2005 pun menggarisbawahi pentingnya Analisis Mengenai Dampak Lingkungan (AMDAL) setiap proyek pembangunan besar seperti pertambangan dan perumahan dan perlu menghormati hak-hak masyarakat setempat atas tanah mereka. ${ }^{46}$ Ikhtiar ekologis Sinode GMIH ini didasarkan pada pertimbangan kesadaran ekologis. Pertama, pesan dan rekomendasi Sidang Sinode XXVI (2007) mengikhtiarkan bahwa sumberdaya alam itu terbatas sementara kebutuhan manusia cenderung tidak terbatas. Selain itu manusia cenderung eksploitatif terhadap sumberdaya alam. ${ }^{47}$ Kedua, semakin disadari bahwa pemanasan global merupakan suatu ancaman serius bagi kehidupan manusia. Menyadari tantangan ekologi maka Sidang Sinode XXVII (2012) mendorong perlunya mengembangkan sikap advokasi ekologi dari pendeta dan warga Jemaat dalam Sinode GMIH. ${ }^{48}$ Selain itu Sinode GMIH melibatkan sejumlah staf dan pimpinan unit di lingkup sinode untuk mengikuti pelatihan dan penyadaran advokasi ekologi seperti pelatihan dan penyadaran tentang bumi bernafas yang diselenggarakan oleh mitra Sinode GMIH. ${ }^{49}$

Ikhtiar ekologis Sinode GMIH di atas didasarkan pada keyakinan teologis, baik seperti yang tertuang dalam pesan dan rekomendasi Sidang Sinode XXV (2002), maupun pemahaman dasar iman dan pokok-pokok ajaran Sinode GMIH hasil Sidang Sinode XXVII (2012), mengikhtiarkan bahwa bumi dan segala isinya adalah anugerah Allah bagi kesejahteraan manusia. Memelihara kelestarian bumi dan segala isinya berarti memelihara kesejahteraan ekonomi manusia. ${ }^{50}$ Keyakinan teologis ini membuat Sinode GMIH pada Sidang Sinode XXVII (2012) dan Sidang Sinode XXVII (2017) memutuskan untuk mengintegrasikan bidang pelayanan lingkungan hidup dengan bidang pelayanan ekonomi. Karena bagi Sinode GMIH bumi dan segala isianya itu sebagai potensi sumberdaya ekonomi bagi kesejahteraan umat manusia. ${ }^{51}$

Dari uraian di atas kita dapat memberi catatan sebagai berikut. Pertama, kepedulian ekologis dalam dokumen-dokumen gerejawi Sinode GMIH lebih bersifat informasi praktis yang belum memiliki landasan teologis yang mendalam. Oleh karena itu, letupan-letupan sejumlah kegiatan seringkali tidak begitu terintegrasi dengan hidup menggereja Sinode GMIH secara liturgis. Itulah sebabnya ikhtiar ekologis ini cenderung mandul di tengah-tengah gempuran ekonomi pertambangan di pulau Halmahera dan pulau-pulau sekitarnya. Malahan terkesan para pelayan Sinode GMIH di jemaat-jemaat di sekitar pertambangan cenderung tidak mengembangkan advokasi profetik untuk mendorong kesadaran iman ekologis operatif dalam kehidupan warga jemaat dan warga masyarakat. Kedua, ikhtiar ekologis Sinode GMIH sangat antroposentris. Bumi dan segala isinya hanya dilihat sebagai potensi ekonomi bagi kesejahteraan umat manusia. Barangkali

${ }^{44}$ Stephanie Dietrich, "For Thus Says the Lord: Prophetic Diakonia as Advocacy Anf Fight for Justice", in Evanggelism and Diakonia in Context, ed. Rose Dowsett et al. (Oxford: Regnum Books International, 2015), 153165.

${ }^{45}$ Keputusan Sidang Sinode XXV GMIH, Wari, 01-06 Juni 2002, 26-27.

${ }^{46}$ Keputusan Rekerta IV GMIH, Hatetabako, 9-12 November 2005, 59.

${ }^{47}$ Keputusan-Keputusan Sidang Sinode XXVI (2007), 191-192.

${ }^{48}$ Keputusan Sidang Sinode XXVI (2007), 182.

${ }^{49}$ Keputusan SMS V GMIH (2016), 39-40.

${ }^{50}$ Keputusan Rapat Kerja III GMIH 2004, 63 dan Keputusan Sidang Sinode XXVII (2012), 85, 116.

${ }^{51}$ Keputusan Sidang Sinode XXVII (2012), 17-18; Keputusan SMS V GMIH (2016), 28, 30, 34 dan Keputusan Sidang Sinode XXVIII (2017), 41-42, 125, 133. 
karena alasan teologis seperti inilah kita dapat memahami "sikap diam" dan "sikap akomodatif" sebagian pelayan Sinode GMIH terhadap kehadiran ekonomi pertambangan yang tidak jarang memarginalisasi dan merugikan masyarakat setempat dan merusak ekositem seperti terjadi di pulau Gebe dan desa Mamoji-Loloda Utara.

Ke depan ikhtiar ekologis Sinode GMIH yang sudah disemaikan pada setiap kali persidangan sinode dalam bentuk sejumlah informasi kegiatan pemeliharaan lingkungan (2002-2017) itu perlu memberi pendasaran teologis yang melampaui pendasaran teologis antroposentris. Selain itu, Sinode GMIH juga perlu mengembangkan suatu Laboratorium Ikhtiar Ekologis seperti dilakukan oleh Kongregasi Suster Dina Santu Yoseph Tobelo melalui program: Eco Learning Peace yang menerjemahkan ke dalam praktik isi ensiklik Paus Fransikus: LAUDATO SI'. ${ }^{52}$ Dalam hal ini, inisiatif Universitas Halmahera (perguruan tinggi milik Sinode GMIH), yang sedang menata lingkungan kampus menjadi kampus berlingkungan konvervasi dalam kerajasamanya dengan Balai Taman Nasional Aketajawi Lolobatan, Kemeterian Lingkungan Hidup Republik Indonesia, kiranya dapat menjadi insentif kesadaran ekologis operatif Sinode GMIH dan warganya. Harapannya, kesadaran iman ekologis berupa beberapa informasi tentang kegiatan memelihara lingkungan melalui keputusan-keputusan persidangan Sinode GMIH periode pelayanan 2002-2017 dapat mewujud dalam praxis hidup menggereja Sinode GMIH dan praxis hidup sehari-hari warga jemaatnya. ${ }^{53}$ Dengan mengambil langkah konkret seperti ini maka Sinode GMIH dapat meragakan identitas eklesialnya sebagai tubuh ekologis Kristus di tengah-tengah masifnya perijinan pertambangan di pulau Halmahera dan pulau-pulau sekitarnya di era otonomi ini. ${ }^{54}$

\section{Merawat Semangat dan Komitmen Iman Sosial Edukasional}

Pada masa Zending, didirikan sejumlah sekolah rakyat untuk mengemansipasi masyarakat pulau Halmahera dan pulau-pulau sekitarnya. Selain itu, didirikan juga sekolah guru desa (opleidingschool) dan sekolah pertukangan (ambachtschool). ${ }^{55}$ Maka mulai awal abad ke-20 (1910) hingga Jemaat-jemaat hasil pekabaran Injil Zending UZV menjadi Sinode GMIH mandiri (1949), terdapat sejumlah sekolah di wilayah pelayanan Sinode GMIH. Antara 1949-1999 Sinode GMIH telah memiliki sejumlah sekolah mulai TK/PAUD hingga perguruan tinggi dalam bentuk Sekolah Tinggi Teologi GMIH di Tobelo (STT GMIH Tobelo). Selama masa krisis (1999-2002) lembagalembaga pendidikan ini telah memerankan peran signifikan bagi masa depan warga jemaat. Jauh sebelum krisis kemanusiaan lembaga-lemnbaga pendidikan ini, khusus Sekolah Menengah Pertama (SMP) dan Sekoloh Menegah Atas (SMA), telah sungguh-sungguh menjadi lembaga pendidikan bagi semua warga masyarakat tanpa membedakan latar belakang agama dan suku. ${ }^{56}$ Dari sidang sinode ke sidang sinode, khususnya tahun pelayanan 2002-2007, percakapan semakin intensif tentang pentingnya pengembangan STT GMIH Tobelo menjadi universitas. ${ }^{57}$

Peningkatan status STT GMIH ini dimaksudkan agar pelayanan sosial edukasional GMIH pada level perguruan tinggi lebih luas jangkaunya. Upaya GMIH ini disambut positif oleh semua lapisan masyarakat yang ada di pulau Halmahera dan pulau-pulau sekitarnya. Sambutan positif

\footnotetext{
${ }^{52}$ Sr. Ladya Lenak, “Eco-Learning Peace Dina Santu Yoseph' (ELP DSY)” (Materi Sharing Pada Konsultasi Online Ekologi Oase Intim Dan Mitranya," 1-6 Agustus 2021.

${ }^{53}$ Bahan Sharing Kelompok Halmahera pada Konsultasi Online Ekologi Oase Inrin dan da Mitranya, 2-4 Agustus 2021 dan Radios Simanjutak, "Pengalaman Advokasi Lingkungan Hidup" (Materi Sharing pada Konsultasi Online Ekologi Oase Intim dan Mitranya, 2-4 Agustus 2021).

${ }^{54}$ Julianus Mojau, "Eklesiologi Tubuh Kristus: Misi Gereja Di Tengah Pandemi Covid-19", Dalam Teologi Pandemi: Panggilan Gereja Di Tengah Pandemi Pandemi Covid-19, ed. Dkk Zakaria J. Ngelow (Makassar: Oase Intim, 2021) 45-88.

${ }^{55}$ James Haire, Sifat Dan Pergumulan Teologis Gereja Di Halmahera 1941-1979, Terjemahan Stephen Suleeman, 1998; Magany, Bahtera Injil Di Halmahera, 120.

${ }^{56}$ Julianus Mojau, "Partisipasi GMIH Dalam Pembangunan Daerah: Kemandirian Adalah Pilar Partisipasi Gereja Dalam Pembangunan Daerah Di Era Otonomi Daerah", Dalam Teologi Politik: Panggilan Gereja Di Bidang Politik Pascaorde Baru, 249 dan Liliane Mojau, "Karya-Karya Sosial Zending UZV Di Halmahera", Dalam Bertumbuh Bersama Dalam Arus Zaman Yang Terus Berubah: Bunga Rampai 70 Tahun Gereja Masehi Injili Di Halmahera.

${ }^{57}$ Keputusan-Keputusan Sidang-Sidang Sinide GMIH antara kurung waktu 2002-2007.
} 
warga masyarakat Halmahera dan pulau-pulau sekitarnya telah mengingatkan dirinya tentang fungsi sosial edukasional sebelumnya yang tidak hanya terbatas untuk warga jemaatnya. Maka sekalipun ada banyak perbedaan pandangan pada saat menyelang pengusulan perubahan nama STT GMIH ke Universitas; namun sebagian besar memilih nama universitas hasil pengembangan STT GMIH itu ramah sosial. Karena, demikian sebagian pandangan yang hidup saat itu, bahwa pilihan nama ramah sosial ini dimaksudkan sebagai bagian dari upaya merawat semangat dan komitmen iman rekonsiliatif. Usaha ini diwujudkan pada tahun 2008 dengan nama: Universitas Halmahera (UNIERA). Selain itu usaha merawat semangat dan komitmen sosial edukasional melampaui batas-batas agama pun diwujudkan dengan kebijakan penerimaan dosen. Hingga sekarang para dosen Uniera bukan saja warga jemaat GMIH dan orang Kristen melainkan juga warga masyarakat bukan Kristen (Islam dan Hindu). Kesadaran iman sosial edukasional lintas iman inilah terus menjadi nafas sosial kampus yang mengambil motto pelayanan edukasionalnya dan ingatan sosial emansipatorisnya: SANTUN (Sederhana, Asri, Nurani Terpercaya dan Unggul Nalar). ${ }^{58}$

Melalui pendidikan tinggi ini jugalah Sinode GMIH mewujudkan panggilan dan fungsi sosial kemasyarakatannya melampaui batas-batas agama. Usaha Sinode GMIH ini dimaksudkan untuk membangun peradaban ruang publik Halmahera yang damai, humanis sekaligus ekologis. Oleh karena itu, semangat dan komitmen iman ekologis ini pun dengan lingkungan kampus Uniera menjadi lingkungan konservasi alam seperti disinggung di atas langkah konkret Sinode GMIH meragakan identitas eklesialnya sebagai tubuh edukasional Kristus untuk perabadan ruang publik Halmahera menjadi ruang publik yang berperadaban humanis dan ekologis.

\section{KESIMPULAN}

Sinode GMIH, selama periode pelayanan 2002-2017, telah menyemaikan, bahkan berusaha merawat semangat dan komitmen iman sosial sebagai bentuk tanggungjawab sosial Sinode GMIH di ruang publik Halmahera. Ditinjau dari pandangan Nanuru tentang nalar fungsi sosial Gereja, Sinode GMIH sudah meletakkan dasar-dasar penalaran rasional pelayanan publiknya di tengahtengah perubahan sosial di era otonomi daerah. Ditinjau dari perspektif Wilfred dan Cariňo, Sinode GMIH sudah, dan sedang, menyemaikan praxis teologi publiknya yang bersifat advokatif, rekonsiliatif, dan lintas agama. Usaha Sinode GMIH ini sangat relevan dan kontekstual di tengahtengah ruang publik otonomi daerah di pulau Halmahera dan pulau-pulau sekitarnya yang masih dibayang-bayangi oleh pengalaman sosial traumatik dan gempuran ekonomi neolib dalam bentuk ekonomi pasar dan ekonomi pertambangan.

Harapannya, persemaian peradaban humanis-ekologis melalui lembaga-lembaga pendidikan, seperti yang diperlihatkan oleh Fakultas Teologi Universitas Halmahera (FT-UNIERA) dan UNIERA pada umumnya, dapat tumbuh menjadi benih-benih yang humanis dan ekologis lintas agama di ruang publik pulau Halmahera dan pulau-pulau sekitarnya. Persemaian dan perawatan semangat dan komitmen iman sosial, sebagai bentuk konkret praxis teologi publik, perlu diperdalam dengan penalaran teologis yang memadai, sehingga praxis teologi publik yang sedang tumbuh dan dirawat melalui persidangan-persidangan Sinode GMIH mendapat pendasaran alkitabiah dan tradisi iman Calvinis yang memadai. Hal ini penting, agar benih-benih praxis teologi publik Sinode GMIH tidak berkesan sekadar rangkain kegiatan tanpa dasar teologis. Selain praxis teologi publik, khususnya pada bidang ekonomi dan ekologi, perlu penerjemahan konkret ke dalam pemikiran teologis programatis terukur dan nyata dalam praktik hidup menggereja Sinode GMIH. Sejatinya, Sinode GMIH telah memiliki pemahaman iman dan pokok-pokok ajaran; namun hal ini belum "berbunyi" dalam praktik akta-akta gerejawi secara liturgis. Terlepas dari catatan kritis ini penulis berpendapat bahwa benih-benih praxis teologi publik Sinode GMIH periode pelayanan 2002-2017 memiliki sumbangan yang signifikan untuk merawat ruang publik

${ }^{58}$ Jerizal Petrus, Broery D.P. Tjaya, and Sirayandris J. Botara, eds., Tentang Sejarah Pengembangan STT GMIH Menjadi Universitas Halmahera Lihat Kesaksian-Kesaksian Para Pelaku Sejarah 10 Ribu Rupiah: Harga Nasi Kucing Bangun Universitas Halmahera-Buku Peringatan HUT V Universitas Halmahera (Yogyakarta: Kanisius, 2013). 
Indonesia yang bersifat majemuk dan selalu diwarnai oleh kekerasan sosial dalam berbentuk. Dengan kata lain, Sinode GMIH telah mengembangkan praxis teologi publik yang dapat menjadi sumbangan signifikan bukan saja untuk merawat ruang publik Halmahera, melainkan juga ruang publik Indonesia di era politik otonomi daerah sekarang.

\section{REFERENSI}

Adeney-Risakotta, Farsijana. "Politics, Ritual and Identity in Indonesia: An Moluccan History of Religion and Social Conflic." Radbound Universiteit Nijmegen, 2005.

Cariňo, Feliciano V. Asian Politics and Ecumenical Vision: Selected Writings Of. Edited by Bnd. Philip L., Wickeri, and Mariana True. Hong Kong: CCA, 2013.

Dietrich, Stephanie. "For Thus Says the Lord: Prophetic Diakonia as Advocacy Anf Fight for Justice", in Evanggelism and Diakonia in Context. Edited by Rose Dowsett, Isabel Phiri, Doug Birdsall, Dawit Olika Terfassa, Hwa Yung, and Knud Jørgensen. Oxford: Regnum Books International, 2015.

Duncan, Christopher R. Violence and Vengeance : Religious Conflict and Its Aftermath in Eastern Indonesia. Ithaca and London: Cornell Universty Press, 2013.

Haire, James. Sifat Dan Pergumulan Teologis Gereja Di Halmahera 1941-1979, Terjemahan Stephen Suleeman, 1998.

—. Teologi Kontekstual Dan Henrik van Dijken Dalam Ziarah Dalam Misi: Buku Penghormatan Pdt. Prof. Dr. Jan Arie Bastiaan Jongeneel. Edited by Karolina Agustien Kaunang. Tomohon: UKIT Press, 2014.

Haire, Mary Christine. "Sosiologi, Pekerjaan Sosial Dan Peranan Pendeta GMIH" Bertumbuh Bersama Dalam Arus Zaman Yang Terus Berubah. Edited by Liliane Mojau, Jerizal Petrus, and Sirayandris J. Botara. Jakarta-Tobelo: BPK Gunung Mulia dan Universitas HalamaheraBPHS GMIH, 2019.

Hontong, Sefnat. "Eksistensi Pusara Dodara: Upaya Hermeneutik Etis-Teologis Bagi Pengembangan Budaya Damai Di Halmahera." Yogykarta-Tobelo: Kanisius dan Universitas Halmahera, 2012.

Julianus Mojau. "GMIH Itu Komunitas Iman Diai", Dalam Bertumbuh Bersama Dalam Arus Zaman Yang Terus Berubah. Jakarta-Tobelo: BPK Gunung Mulia dan Universitas Halamahera-BPHS GMIH, 2019.

Lenak, Sr. Ladya. "Eco-Learning Peace Dina Santu Yoseph' (ELP DSY)" (Materi Sharing Pada Konsultasi Online Ekologi Oase Intim Dan Mitranya," 2021.

Magany, M.Th. Bahtera Injil Di Halmahera. Tobelo: GMIH, 1984.

Mojau, Julianus. "Eklesiologi Tubuh Kristus: Misi Gereja Di Tengah Pandemi Covid-19", Dalam Teologi Pandemi: Panggilan Gereja Di Tengah Pandemi Pandemi Covid-19. Edited by Dkk Zakaria J. Ngelow. Makassar: Oase Intim, 2021.

- Ke Arah Pengembangan Teologi Publik Ke-Halmahera-an", Dalam Menggereja Dalam Konteks Halmahera: 65 Tahun Dan Purnatugas Pdt. Arkhipus Dujubasa. Edited by Imelda Kahiking, Stenling F. Korois, and Marton Tasiringan. Tobelo: Fakultas Teologi Universitas Halmahera, 2020.

_. "Partisipasi GMIH Dalam Pembangunan Daerah: Kemandirian Adalah Pilar Partisipasi Gereja Dalam Pembangunan Daerah Di Era Otonomi Daerah", Dalam Teologi Politik: Panggilan Gereja Di Bidang Politik Pascaorde Baru, 249, n.d.

Mojau, Liliane. "Karya-Karya Sosial Zending UZV Di Halmahera", Dalam Bertumbuh Bersama Dalam Arus Zaman Yang Terus Berubah: Bunga Rampai 70 Tahun Gereja Masehi Injili Di Halmahera. Edited by Liliane Mojau, Jerizal Petrus, and Sirayandris J. Botara. JakartaTobelo: BPK Gunung Mulia dan Universitas Halamahera-BPHS GMIH, 2019.

Muksin, Dafrin. "DAMPAK SENGKETA WILAYAH KABUPATEN HALMAHERA BARAT DAN HALMAHERA UTARA TERHADAP PENGELOLAAN PEMERINTAHAN DI DESA BOBANEIGO." AL-IMARAH: Jurnal Pemerintahan dan Politik Islam 6, no. 42 (2021): 143155. 
Nanuru, Ricardo F. "Fungsi Sosial Gereja Menurut Konsep Rasionalitas Jürgen Habermas", Dalam Politik Sang Guru: Buku Penghormatan Pdt (Em.) Hans Alexander Annu, M,Th. Edited by Anselmus Puasa, Arkipus Djurubasa, and Broery D.P. Tjaya. Yogyakarta: Kanisius, 2014.

Nataniel, Demianus. "Paulus Dalam Konflik Antarumat Beragama: Membaca Konflik Di Maluku Utara Berdasarkan Sikap Nasionalisme Paulus." GEMA TEOLOGIKA: Jurnal Teologi Kontekstual dan Filsafat Keilahian 4, no. 2 (2019): 195.

Petrus, Jerizal, Broery D.P. Tjaya, and Sirayandris J. Botara, eds. Tentang Sejarah Pengembangan STT GMIH Menjadi Universitas Halmahera Lihat Kesaksian-Kesaksian Para Pelaku Sejarah 10 Ribu Rupiah: Harga Nasi Kucing Bangun Universitas Halmahera-Buku Peringatan HUT V Universitas Halmahera. Yogyakarta: Kanisius, 2013.

Putjutuju, Frederick R. Esa Moi: Teologi Rekonsiliatif Di Tengah Kemajemukan Halmahera. Yogyakarta: : Lintang, 2012.

Ruddy Tindage. Damai Yang Sejati: Rekonsiliasi Di Tobelo-Kajian Teologi Dan Komunikasi. Jakarta: YAKOMA-PGI, 2006.

Sugiyono. Metode Penelitian Kuantitatif-Kualitatif Dan R \& D. Bandung: Alfabeta, 2009.

Wahono, Francis. Ekonomi Politik Daulat Rakyat Indonesia: Pancasila Sebagai Acuan Paradigma. Jakarta: Kompas, 2020.

Wilfred, Felix. Asian Public Theology: Critical Concerns in Challenging Times. Delhi: ISPCK, 2010.

Wowor, Jeniffer Pelupessy. "Partisipasi Pendidikan Kristiani Di Ruang Publik Dalam Menunjang Deradikalisasi." Kurios 7, no. 1 (2021): 108.

Zanden, Jan Luiten van, and Daan Marks. Ekonomi Indonesia 1800-2010: Antara Drama Dan Keajaiban Pertumbuhan. Jakarta: Kompas dan KITLV-Jakarta, 2012.

Keputusan Sidang Sinode XXV GMIH Wari, 01-06 Juni, 112 (2002). 